\title{
A Cognitive Inquiry of the Choreographic Philosophy of Process Day
}

\author{
Xiao Liu \\ School of Music and Dance \\ Sichuan Technology and Business University \\ Chengdu, China
}

\author{
Zhong Deng \\ Foreign Language School \\ Southwest Minzu University \\ Chengdu, China
}

\begin{abstract}
This paper intends to look at Process Day, a highly appraised contemporary dance performed during the 2017 Edinburgh Festival Fringe from a cognitive perspective with an accentuated focus on its choreographic philosophy and the means how it is represented and communicated. This paper argues that the artistic merits of Process Day are rooted in humans' increasing reconciliation of the body-mind relations, enhanced by a tangible confrontation with gender duality, and culminated in an obsession as to how to link hidden sentiments and desires to the ultimate meaningfulness of life.
\end{abstract}

Keywords-Process Day; cognition; gender duality; meaningfulness of life

\section{INTRODUCTION}

Presented by Scottish Dance Theatre, and choreographed and created by Sharon Eyal \& Gai Behar, Process Day was an immediate and enormous success at the 2017 Edinburgh Festival Fringe. As part of British Council Edinburgh Showcase, it functions as an artist window on what contemporary dance is like in today's Britain (especially in Scotland). Process Day features "a sensory experience" in which dancers are transformed into "sleek, androgynous, nocturnal beings" who are dedicated to "the universal drive of striving for fulfillment and release" (quoted from the official brochure of Process Day). However, such a simplified version of introduction is far from satisfactory in terms of providing a thorough and crystallized interpretation of what is intended, performed, and communicated in this show. Moreover, partly because this dance is relatively new, not much research has been launched on its choreographic, artistic, ideological or social aspects as previously has been done on many other works. In other words, we have not gained much scholastic insight into this dance although it has won wide-ranging supports from the worldwide audiences. Therefore, this paper attempts to probe into Process Day, shedding a light on its choreographic philosophy which is embodied by an array of techniques, devices and settings in close associations with characters and plots, and which ultimately points to the theme it is obliged to demonstrate, in the hope that we may truly come to comprehend the deeplyseated concerns of the choreographers and producers.

\section{BODY AND COGNITION IN CHOREOGRAPHY}

\section{A. Body and Movement: A Structuralist View}

When it comes to dance and choreography, body and movement are of fundamental importance as dance itself is an event composed by and characterized of people's conception and manipulation of human body as well as ways and patterns of its movements. Similarly, choreography is meant to seek laws and modules as to how body and movement are coordinated and inter-played in a dance for the purpose of communicating emotions and ideas, a task which other forms of art are deemed as either inappropriate or ineffective to perform. Ever since choreography has established itself as an independent discipline, substantial discussions and large numbers of points have been made on body and movement among which two views are worth examining to facilitate our further elaboration. The first one is a structural view which highlights the isomorphism between body and the physical world. That is, human body shares the same structure and functioning mechanism with the world we are living in, thus movements body shall conform to the laws of movements of the world. This perception was a clear manifestation of structuralist linguistics's influences on arts and humanities as observed by F. R. Jameson (1972) that (structuralist) linguistic paradigms should be the model of all scholarly endeavors as language enjoys an unparalleled position among all the elements that constitute consciousness and society in an ontological sense. The ambitious analogy between the flesh and the world did provide researchers with a brand new perspective to look at dance via its structural resemblance with and deviation from what is known about the physical setting of the environments, but the drawbacks of so doing are intolerably obvious: 1) too much attention to the form has dwarfed many desired inquiries into the meaningfulness of dances; and 2) excessive preoccupation with worldresemblance/deviation has overshadowed the individuallevel motivations to seek themes which were excluded in the structuralist models. Thus, the structuralist approach seems incompetent to render all the essentials about body and movement.

\section{B. A Cognitive Revolution}

In the 1970s, the thriving cognitive science has been widely accepted by scholars in the fields of arts and humanities as the systematic and in-depth investigation into 
mind and cognitive mechanisms involved in almost all human behavior has promised an optimized even unified interpretation for issues which have been continuously discussed in such disciplines. Cognition has been regarded as a scientifically grounded key to meaning, emotions and aesthetics (Aldama \& Hogan 2014). Not surprisingly, choreographers and dance theorists have begun their own exploration as to how cognition might help their creation and criticism of dances. Central to their concern was still body and movement, but their focus was not on worldresemblance/deviation, but on an embodied experience of humans (dancers in particular) in their day-to-day sensorbased interaction with the world. In other words, body is not simply a physical being that is given commonality with other forms of physical beings so as to acquire its importance, nor is movement merely a manipulatable and translatable mechanism to transcribe the world so as to highlight its aesthetics. This change meant a lot to theories and practice of dance in that it profiles two notions which proved to have shaped how dance is understood. Firstly, what is intrinsically connected to body is not the world, but the mind. Precisely, it is through the mind (as a bridge metaphorically) that body inter-plays with the world. In other words, there is no way to interpret body-world relations without addressing body-mind ties in the first place. Secondly, any academic exploration of dance should be devoted to not only forms, but also meaning. Meaning, despite its inaccessibility as mentioned by Bloomfield (1921), is in fact approachable and analyzable under the framework of cognitive semantics. Simply put, meaning is viewed as the conceptualization based on humans' embodied life experience (Langacker 2008). Upon accepting these two perceptions, we are able to develop such a new interpretive pattern of dealing with dance and choreograph: mind-body ties-conceptualizationmeaning/form.

\section{MIND-BODY TIES IN PROCESS DAY}

Based on the speculation that mind accounts for behavior via cognitive mechanisms, our discussion begins with the title "Process Day". What seems ironic at the first glance is that in this dance there is neither "process" (ten dancers in total who rarely appear as a whole group) nor "day"(dancers transformed into nocturnal beings). So why is it named like this? To answer this question, we have to draw on the mindbody relations represented in the diction. "Process" is normally a noun when referring to 1) "a series of actions that are done in order to achieve a particular result", 2) "a series of things that happen naturally and result in gradual change", or 3) "a method of making or producing goods"(Longman Dictionary). Given the obscure context in collocation with "day", it is not surprising that all the three meaning items fit grammatically. But a closer look may reveal the subtle difference in relation to body and mind. In items 1) and 3), "actions...done" and "making/producing" are at the core respectively, while in item 2), "things" plays the central role. This difference represents a distinction between verbcentered and noun-centered constructions, with the former emphasizing bodily endeavors to achieve a goal deliberately as opposed to the latter that accentuates static existence subjected to changes of physical dimensions (Langacker 2008).

Therefore, we may find the first facet of the mind-body ties in this dance: there are two different mind-sets that underlie two different bodily choices. The first choice is to strive for goals out of a purposeful mind; the other is to stand idle based on a passive or dormant mentality. This way, the choreographers manage to bring the speculators into an intangible dilemma---and probably for a better delivery of such an intention, the color-scheme for the costumes of the dancers are black and white without a fail, somewhat successful in rendering a tangible reference for the viewers. The second facet of the mind-body ties in this dance lies in the use of "day" to depict the nocturnal beings' tempo-spatial dimension. "Day" is conceptually associated with the sun, thus with the brightness. Viewed from a metaphorical perspective by means of which the meaning of things in a cognitive domain is projected onto another cognitive domain which is activated by internal resemblance or associations (Lakoff 1987), "day" is connected with the feelings or emotions of being cheerful and joyful (in the domain of emotions, for example). And naturally, such a mind-set is highly likely to be translated into facial expressions such as smiling or giggling or into bodily reactions such as jumping or yelling. However, in this show nothing like this is presented; instead, what is consistently seen on the stage is grim and serious faces together with sometimes repetitive and mechanical movements in response to the rhythm of music. Hence, we may be able to illustrate the second facet as a conflict between mind and body. Such a conclusion seems to contradict the mind-body harmony mentioned above, but indeed it points to a state of unconsciousness and absent-mindedness which are not rare occurrences in life, and which normally result in losing control of behavior and of order (physical, social or ethnic). In this dance, we find several movements and poses are not designed in accordance with usual norms that suit bodily physics; in many cases, exaggerating distortions or twisting are put in places where dancers are rendering somewhat extreme facial expressions as well, all contributing to an artistic rendering of mind-body discrepancy.

On the whole, a cognitive investigation paves the way for a clarification of mind-body relations in Process Day: 1) When mind stays in harmony with body, there is a dilemma; 2) When mind loses control of body, there is chaos. Obviously, neither of these is desirable for the fulfillment of life, thus arguably dancing in the darkness in black-andwhite costumes in mechanical, distorted manners without any change in facial expression seems to be a desirable manifestation of this undesirable and inconvenient truth of life.

\section{GENDER DuALITY AND COGNITION}

An exceptionally marked feature of Process Day is the continuously highlighted sense of gender duality. Our discussion is therefore central to such a concern as to why and how gender duality fits in and substantiates meaning of this dance. 


\section{A. Gender Duality: Manifestations}

The most important manifestation of gender duality lies in Kieran Brown, who acts as the central role with physically robust masculinity as well as a behavioral pattern characterized of the softness out of feminist seductiveness. No doubt his performance is excellent, but behind the excellence, there is so much more to elaborate on. In short, there is a two-facet gender duality observable in the show, one being conspicuous with deliberately marked androgynous signals while the other being a concealed message communicated on a conceptually abstracted level. More specifically, the former is what the audiences are seeing - sleek dancers in the dark, sexually blurred behavior and so on; but the latter makes such a difference that has escalated this dance to a height where matches are few and reflections are both many and profound. To put it simply, sex serves not only as the theme but also as a specially-designed conceptual metaphor in this dance. Metaphor itself is not unusual as many cognitive linguists have observed, but when it comes to an investigation of metaphor, one is inclined to identify two domains respectively out of two distinctive categories before illuminating how things in one domain is projected onto the other and how language structures document such a projection. The unusual point of metaphor in Process Day, however, is that the domains that are activated for conceptual projection do NOT separate from each other into different categories; instead, they are of the same category: human body. In other words, movements and poses featuring masculinity are carefully extracted and conceptually transformed into those characteristic of females, both represented on the same human body and alternated at certain intervals. If such androgynous presentations are not striking enough, what really matters is that the male and female features of the same human boy are able to communicate with each other by movements, especially by the changes in the distance between the dancer's arms and in the frequency with which his hands touch his own body. Thus, a rather clear development pattern can be identified in Kieran Brown's performance that highlights the alternation and combination of strong manliness, weak manliness, weak womanliness and strong womanliness. In response to this pattern, solo and group dance are alternately employed by the choreographers, forming the overall logic to govern all the scenes and plots.

\section{B. Gender Duality: Categorization and Cooperation}

Briefly, gender duality in Process Day is about a visually androgynous and conceptually intra-communicating human body. But why choreographers had to bother themselves to put forward such a concept? In what way does gender duality as a physical and conceptual token communicate a broad view and profound concern which help make up with the totality of meaningfulness of this dance?

We feel obliged to address these problems from two angles: 1) the prevalence reference to gender in contemporary dance; 2) the philosophical insight into duality and dichotomy. For the first issue, we are convinced that there is a cognitively traceable link between gender and what is meant by "contemporary". According to many postmodernist theorists, especially advocates of Derrida and
Deconstructivism, "Western metaphysical essence" is dubious and ungrounded as it has been trying to see the world and everything concerned with it as well defined and organized (Cooper 1989). Thoughts like this have prevailed especially in linguistics, literature and arts because they somewhat mirror what the world is being like in modern times: lesser absolutely drawn division between what used to be clearly divided, more than one explanation for issues which were clearly interpreted, newly emerging thoughts and behavioral norms which do not fall into or stem from any of the traditionally endorsed areas... Among all that it "deconstructable", however, sex seems to be the most accessible and sensational. By "accessible" we mean sex used to belong to the very category of western metaphysical essence as an easily definable representation of human beings and many other sub-representations are simply based on gender differences; by "sensational" we mean sex has been invariably incorporated into themes of literature and arts, as it was advocated by Freudian scholars that sex explains and underlies all human desires and motives which are needed by literary and artistic creation in terms of enhancing appeals to audiences. That is why contemporary dance, since the very beginning, has drawn heavily on sexrelated thoughts and expressions. In other words, now that sex functions as part of the essential workings of the world as well as of the central concern of people, creators and choreographers enjoy a natural affinity to sex-related issues by regarding sex as the most straightforward and transparent means of thinking and communicating. Enhanced by Deconstructivism, sex is being endowed with more uncertainty and unpredictability despite its ontologically and perceptibly based stability, providing choreographers with unlimited possibilities of re-interpreting sex and its meaning from a wider range of perspectives.

For the second issue, we deem it necessary to expound on the duality and dichotomy respectively before talking about gender duality in Process Day. Simply speaking, "duality" deals with a state of being united or combined with different layers or aspects of components reserved, while "dichotomy" refers to a state of splitting the wholeness into two with each of them marking a distinction from or conflict with the other. Both the concepts have profound cognitive implications. Since Aristotle, well-informed people in the west have been used to a yes-no question based criterion of categorizing objects into various groups, practically a means advocated by classic philosophy as to how the world shall be cognized (Mckeon 1992). In this sense, "dichotomy" is the way the knowing, at least a way of simplifying the mass of characteristics of objects into an analysis of two opposing items as "male" and "female" in the categorization of humans and "Yin" and "Yang" in the categorization of Nature (a Chinese tradition). Compared with "dichotomy", "duality" represents a deeply-rooted fear for simplification, arguing such a way of knowing the world may not bring about desired knowledge of the world as in many cases the world is more complicated than has been categorized, say, the difficulty in telling good from evil, the dilemma of distinguishing right from wrong, and, of course, the uncertainty in telling between two genders. Therefore, "duality" is semantically of an unwillingness of making 
simplifications, with its aim being a cognitive pursuit for what is true there in the world as well as in human beings.

Based on discussions on the two issues, our understanding of gender duality of Process Day is now comparatively well grounded: humans are by no means free from categorization (in terms of genders, races, religions...), but such categorizations are dangerously simplistic and misleading, thus cooperation by what are categorized and separated is the way humans should seek in order to see, accept and enjoy the complexity of being humans. More precisely, the fullness of life which an individual is supposed to pursue is not simply based on clearly divided categories of knowledge which are often imposed and institutional merely for the sake of convenience, but on the realization and acceptance of complexity and diversity which are essentially subjective and experienced in response to how human mind treats and interacts with the world. But here arises another question: "complexity" in some cases is associated with disorder, as several pieces literature and drama have shown both in ancient and modern times. A common explanation for disorder is that the creators may want to arouse the audiences' reaction of being dizzy or disgusted as needed by aesthetic or emotional appeals (Aladama \& Hogan 2014), but we believe it is not always the case. Starting from the semantic analysis above, we find "duality" does not mean "blending" or "mixing" where components lose their original states and are lurched into an uncontrollable situation. Obviously, in Process Day, features of males and females in the same human body do not mean to mingle into a scenario of disorder; instead, they are untied while maintaining their original beings, by means of which they are offer possibilities of communicating with each other.

\section{CONCLUSION}

We have answered two questions on the basis of a preliminary scholastic investigation into Process Day. Firstly, how body and cognition have interacted with each other so as to present movements and poses which seem not only stunning but also though-provoking? Secondly, how gender duality is selected, highlighted and re-interpreted as a means for humans to know the self and to achieve meaningfulness of life? More importantly, in terms of methodology, we believe cognitive science is of great importance and feasibility in addressing artistic concerns, especially contemporary dance which places an exceptional emphasis on human mind and how it relates to the emotions and aesthetics. Our discussion of the choreographic philosophy of Process Day serves as a daring probe into what arts and life are really about.

\section{REFERENCES}

[1] Bloomfield, B. "Sapir, Edward: An Introduction to the Study of Speech." Classical World A Quarterly Journal on Antiquity,1921.

[2] Cooper, R. "Modernism, Post Modernism and Organizational Analysis 3: The Contribution of Jacques Derrida." Organization Studies10.4(1989):479-502.

[3] Hogan, Patrick, and F. L. Aldama. Conversations on Cognitive Cultural Studies-Literature, Language and Aesthetics. Columbus, Ohio: The Ohio State University Press, 2014.
[4] Jameson, R. Structuralist Semiotics, trans. Qu Tiepeng, Shanghai Translation Publishing House, 1987.

[5] Lakoff, G. Women, Fire and Dangerous Things. Chicago University Press, 1987.

[6] Langacker, R.W. Cognitive Grammar: A Basic Introduction. Oxford: Oxford University Press, 2008.

[7] Mckeon, R. P. "The Basic Works of Aristotle." Aristotles Works8.19(1992):1-21. 